\title{
ORIENTAÇÃO E SUPERVISÃO ESCOLAR
}

\author{
Emilia Monego ${ }^{1}$ \\ Fabio Lopes Schwertz ${ }^{2}$ \\ Fernanda dos Santos Medeiros ${ }^{3}$ \\ Juliano Carvalho Barros ${ }^{4}$ \\ Maike Stredr Ferreira Machado ${ }^{5}$ \\ Rodrigo Donizeti da Silva ${ }^{6}$
}

RESUMO: Neste artigo serão abordados temas sobre a orientação e supervisão escolar, a metodologia de ensino e dentro dela um tema e seus objetivos cujo principal é conhecer a função e a prática do gestor escolar, observando sua relação no processo de ensino-aprendizagem. O método utilizado para a confecção do artigo foi a pesquisa documental.

Palavras-chave: Orientação. Supervisão. Gestão.

\section{INTRODUÇÃO}

Este artigo tem como área de concentração metodologias de ensino. Como objetivos serão abordados temas para conhecer e entender a prática do orientador e do supervisor escolar. O seu objetivo é a qualidade do ensino.

\section{DESENVOLVIMENTO}

Segundo Malaguzzi (1999, p. 85) “ a escola compara-se a um atelier, um espaço rico em materiais, como uma arca do tesouro, dos trabalhos dos alunos e da pesquisa dos professores”, e, por ser um local lúdico e prazeroso, ajuda aos alunos a encontrar os seus próprios estilos de troca com os colegas, tanto do ponto de vista de seus talentos e competências, quanto de suas descobertas.

\subsection{O SUPERVISOR ESCOLAR}


A identidade do supervisor pedagógico é construída na relação com o outro, pois tanto os supervisores quanto os professores planejam e executam suas práticas interligadas.

Rodrigues (201I apud Santos 20II) cita alguns princípios do supervisor pedagógico:

- Lucidez quanto à Educação: o supervisor deve ter a ideia clara do que é educação;

- Segurança: o supervisor deve ter conhecimento sobre educação e sobre sus prática para agir com segurança diante de todas as situações;

- Consciência do papel das suas funções: é necessário que o supervisor saiba qual o seu lugar na escola e qual o seu papel, pois assim terá o respeito dos demais profissionais, dos professores e por consequência contribuirá para um ambiente escolar harmonioso;

- Espírito crítico: o supervisor deve ter o espírito crítico para também o transmitir aos seus colegas, provocando na equipe escolar uma capacidade de reflexão e revisão permanente;

- Racionalidade: usar a razão para não complicar aquilo que é simples, ser um simplificador, visando o alcance das finalidades e objetivos do processo educativo;

- Diligência: dimensão amorosa, que traz um trabalho jovial, alegre, estimulante e cooperativo, sem glórias ou críticas, baseado no reconhecimento, motivação, reavaliação e reconhecimento; e

- Liderança: deve exercer sua liderança, não de forma autoritária, mas comandando, orientando e estimulando a equipe para que juntos possam alcançar os objetivos educacionais;

O supervisor deve desenvolver competências e habilidades para gerir uma equipe, usando de sensibilidade e criatividade para assim exercer sua função que não é de "supervisionar" como seu nome nos leva a pensar, mas sim de acompanhar a rotina dos professores, buscar inovações para suas práticas pedagógicas se houver necessidade, servir de apoio ao professor quando ele precisar de ajuda. Não criticar o trabalho desse profissional, mas sim buscar formas e alternativas de trabalho que possam garantir um bom resultado ao trabalho do professor, construindo assim a aprendizagem dos alunos.

Para que o supervisor possa exercer, de fato, sua função é necessário que este tenha algumas características. Santos (20II) cita 20 características que um supervisor deve ter, são elas: 
- Ser humilde;

- Dinâmico;

- Auxiliador;

- Orientador;

- Acessível;

- Eficiente;

- Renovar seus conhecimentos;

- Inovador;

- Flexível;

- Responsável;

- Respeitar a opinião dos outros e aproveitá-las;

- Evitar impor sua filosofia;

- Aceitar as diferenças;

- Respeitar as confidências;

- Dar satisfação ao grupo sobre as decisões tomadas;

- Reconhecer seus erros e limitações;

- Auto avaliar-se constantemente;

- Encorajar a equipe;

- Ter autocontrole; e

- Ser mestre e aprendiz.

\section{I.I Supervisão Pedagógica: Princípios e práticas}

No contexto brasileiro a supervisão tem uma concepção a apresentar-se como uma prática relativamente recente. Remonta aos anos 70 e surgiu "no cenário sócio políticoeconômico, historicamente, como função de controle” (SILVA, 1998, p. 48). Em nome da eficiência e da eficácia defendidas por abordagens de influências Tayloristas que subjazem as tecnocratas, que valorizam a racionalidade, o supervisor é considerado o instrumento de execução das políticas centralmente decididas e, simultaneamente, o verificador de que essas mesmas políticas são efetivamente seguidas. Designado muitas vezes por supervisor escolar, é 
responsável pelo funcionamento geral da escola em todos os setores: administrativo, financeiro, cultural e de serviços.

Porém, como reflexo do movimento de capacitação e autonomização do professor e da própria escola como coletivo de profissionais, começam hoje a ter-se outra visão do papel do supervisor. Ao superpoder orientador e controlador contrapõe-se uma concepção mais pedagógica da supervisão concebida como uma construção com os professores, do trabalho diário de todos na escola. O supervisor passa assim a ser parte integrante do coletivo dos professores, e a supervisão realiza-se em trabalho de grupo.

$\mathrm{Na}$ definição de Rangel, a supervisão passa de escolar, como é frequentemente designada, a pedagógica e caracteriza-se por "um trabalho de assistência do professor, em forma de planejamento, acompanhamento, coordenação, controle, avaliação e atualização do desenvolvimento de processo ensino-aprendizagem" (1998, p. 13 e p.I4). A sua função continua a ser política, mas é uma função sociopolítica crítica, evidenciada em afirmações como

Confirmam-se, então, a ideia e o princípio de que o supervisor não é um "técnico"encarregado da eficiência, do trabalho e, muito menos um "controlador de produção"; sua função e seu papel assumem uma posição social e politicamente maior, de líder, de coordenador, que estimula o grupo à compreensão - contextualizada e crítica - de suas ações e, também de seus direitos. (RANGEL, 1997, p. 151).

A supervisão pedagógica dirige-se ao ensino e à aprendizagem. O seu objetivo é a qualidade do ensino, porém os critérios de apreciação da qualidade não são impostos de cima para baixo em uma perspectiva preceituaria acriticamente aceita pelos professores, mas na interação entre o supervisor e os professores. Embora a tônica seja colocada na relação ensinoaprendizagem, esse processo ocorre no ambiente escolar, pelo que nem o supervisor, nem os professores podem circunscrever do que acontece na sala de aula, pois essa funciona como um microcosmo de um universo mais amplo, constituído pela escola e pela comunidade. Daí a necessidade sentida por uma supervisora em grupos de reflexão, que afirma: "O supervisor é o sujeito que faz a leitura da escola na sua totalidade” (Medina, 1997, p. 18).

2.I.2 O Repensar da nossa Sociedade

Falta ao Brasil um projeto de país, um projeto que leve o Estado a rumos de longo prazo. Vivemos uma circunstância histórica inusitada: nem as elites, nem os demais 
segmentos da sociedade tem conseguido articular um projeto que consiga unir o país em torno de um modelo que permita encurtar a distância entre os mais ricos e os mais pobres. Essa separação se faz por um fosso abismal. É imenso o distanciamento que os segmentos sociais marginalizados e a possibilidade de inclusão social. A nossa capacidade de diálogo entre o país moderno e o país tradicional.

2.I.3 O Estudo Como Prática de Supervisão

Ao falar de supervisão é preciso situá-la quanto ao nível e ao âmbito de ação. A supervisão de qual se fala neste texto é a que se realiza na escola, integrada à sua equipe docente, com âmbito de ação didática e curricular. É preciso, entretanto, reconhecer outros níveis - centrais e intermediários - da função supervisora que incumbe ações de natureza pedagógica, administrativa e de inspeção.

O supervisor pedagógico escolar faz parte do corpo de professores e tem a especificidade do seu trabalho caracterizado pela coordenação - organização em comum - das atividades didáticas e curriculares e a promoção e o estímulo de oportunidades coletivas de estudo. Portanto, a coordenação é uma função que se encaminha de modo interdisciplinar.

A coordenação das atividades didáticas e curriculares é interdisciplinar tanto em seus 314 fundamentos quanto no sentido da promoção de articulações entre os elementos do processo ensino-aprendizagem: professores, alunos, objetivos, conteúdo, métodos, avaliação, recuperação e contexto.

2.I.4 O Estudo Como Prática de Supervisão

A dinâmica do processo didático e do conhecimento que se ensina, aprende e constrói na escola, solicita que o supervisor incentive o estudo e promova esse hábito. Segundo Bourdieu (1989), essa predisposição adquirida, com determinação e prática, incorpora aos conteúdos específicos quanto aos que ampliam e aprofundam bases, encaminhamentos e concepções do ato educativo de ensinar e aprender, que caracteriza e especificidade da escola e do conhecimento que deve garantir.

A função, a missão de estudar requer do supervisor a visão geral dos fundamentos, princípios e conceitos do processo didático. Esse processo por natureza tem como alguns de 
seus temas significativos de estudo, o sentido humano, social, educativo e das relações pessoais. É preciso, pois, voltar a afalar em afetividade, emoção e prazer.

Embora se considere que aprender requer disciplina, organização, atenção, concentração, trabalho, é preciso pensar no ser humano e seu direito fundamental de ser feliz. Assim a disciplina, o trabalho de ensinar e aprender não exclui a finalidade e o direito da vida humana prazerosa.

A assimetria na relação entre o professor e o aluno é inerente à autoridade do professor, que lhe é conferida pela competência no conteúdo. Nesse sentido, a linearidade, referida à equivalência de funções e competências que são objetivos do ensino-aprendizagem, dá lugar a posições e papeis assimétricos, observando-se a "autoridade" de quem tem "algo mais" a oferecer, da própria condição - e requisito - de conduzir e orientar o processo didático: o professor.

2.1.5 Um Olhar Histórico Sobre a Supervisão

A ideia de supervisão surgiu com a industrialização, tendo em vista a melhoria quantitativa e qualitativa da produção antes de ser assumida pelo sistema educacional, em busca de um melhor desempenho da escola em sua tarefa educativa. Para Souza (1974), a 315 supervisão é fruto da necessidade de melhor adestramento de técnicas para indústria e o comércio, estendendo-se posteriormente aos demais campos: militar, esportivo, político, educacional e outros, com o objetivo de alcançar um bom resultado do trabalho em realização.

Durante o século XVIII e o princípio do século XIX, a supervisão se manteve dentro de uma linha de inspecionar, reprimir, checar e monitorar (Viles; Lovell, 1975). Somente em I84I, em Cincinnati, surgiu a ideia de supervisão relacionada ao ensino, sendo que até o ano de I875 estava voltada primordialmente à verificação das atividades docentes (AFONSO ET. AL. 1975). No final do século XIX e início do século XX, a supervisão passou a se preocupar com o estabelecimento de padrões de comportamento bem definidos e de critérios de aferição do rendimento escolar, visando à influência do ensino.

No começo do século XX, pode-se verificar a utilização dos conhecimentos científicos na melhoria de ensino e na medida dos resultados de aprendizagem dos alunos. A supervisão, 
então, se propõe a transmitir, explicar, mostrar, impor, julgar e recompensar (VILES; LOVELL, 1975).

É interessante pensar que, com a implantação dos Parâmetros Curriculares Nacionais (Brasil, MEC, 1997) a supervisão educacional poderá ser uma grande aliada do professor na aplicação associada à avaliação crítica, desses parâmetros. Mas para que se possa alcançar esse objetivo, é necessário que essa supervisão seja vista em uma perspectiva baseada na participação, na cooperação, na integração e na flexibilidade. Nesse sentido, reconhece-se a necessidade de que o professor e o supervisor sejam parceiros, com posições e interlocuções definidas e garantidas na escola.

\subsection{ORIENTADOR EDUCACIONAL}

Para Penteado (1976, p. 12),

Orientar é auxiliar o aluno a proceder aos ajustamentos necessários, relativos à escola em particular e à vida extraescolar em geral, procurando promover mudanças de comportamento duradouros e prospectivas que permitam ao jovem enfrentar o futuro $\mathrm{e}$ as transformações com adequado preparo. $\mathrm{O}$ orientador, tomando como ponto de partida o estudante, visa a formação do homem.

Com o passar do tempo a escola e os professores evoluíram e isso faz com que os 316 alunos esperem mais das instituições de ensino e do Orientador Educacional. Seguindo essa linha de evolução, o orientador se tornou mais atuante e tomou consciência do seu papel na sociedade. Segundo Pianezzer (2013), seguem algumas características necessárias para exercer bem a função:

- gostar de lidar com todo tipo de gente, de diferentes idades e não ter nenhum tipo de preconceito;

- servir a comunidade escolar auxiliando todos os alunos;

- saber ouvir, compreender, aceitar, aconselhar e, principalmente, respeitar as pessoas que fazem parte de seu contexto educacional;

- exercer uma liderança democrática, cooperativa e participativa; e

- ser um líder exemplar e conquistar o respeito de seus orientados, sem ser autoritário.

\section{CONCLUSÃO}


Após o conhecimento adquirido nesta pesquisa, verificou-se que as funções de orientador e supervisor educacional são de extrema importância no processo de ensinoaprendizagem. Eles devem ter uma boa relação com os professores no que se refere ao trabalho em equipe, porque um deve auxiliar o outro.

Portanto, para ser um bom orientador ou supervisor é necessário ter conhecimentos sobre o assunto para demonstrar confiança aos alunos. Algumas características e habilidades como: ser mestre e aprendiz, acessível, eficiente, inovador, etc. devem ser acentuadas também, naquele que se propõe assumir uma função tão importante como a de supervisor ou orientador educacional.

\section{REFERÊNCIAS}

ALARÇÃO, Isabel. Supervisão Pedagógica: Princípios e Práticas. II ed. São Paulo: Editora Papirus, 20II.

BUSS, Rosinete Bloemer Pickler. Gestão Escolar. Indaial: Uniasselvi, 2013.

MALAGUZZI, L. Histórias, ideias e filosofia. Porto Alegre: Artmed, 1999.

PIAGET, J. Psicologia da inteligência. Rio de Janeiro: Zahar, 1997.

URBANETZ, Sandra Terezinha; SILVA, Simone Zampier da. Orientação, Supervisão Escolar: Caminhos e Perspectivas. I ed. São Paulo: Editora IBPEX, 2008.

VIGOTSKY, L.S. Pensamento e linguagem. São Paulo: Martins Fontes, 1985. 